\title{
Hyperbaric Oxygen Enhances Collagen III Formation in Wound of ZDF Rat
}

\author{
Jiř́ RŮŽIČKA ${ }^{1,2}$, Martina GRAJCIAROVÁ ${ }^{2,4}$, Lucie VIŠTEJNOVÁ2 ${ }^{2}$ Pavel KLEIN ${ }^{2}$, Filip \\ TICHÁNEK ${ }^{2,3}$, Zbyněk TONAR ${ }^{2,4}$, Jiří DEJMEK ${ }^{1,2}$, Jiří BENEŠ ${ }^{1,2}$, Lukáš BOLEK ${ }^{1,2}$, Robert \\ BAJGAR $^{1}$, Jitka KUNCOVÁ ${ }^{1,2}$
}

${ }^{1}$ Department of Biophysics, Faculty of Medicine in Pilsen, Charles University, Pilsen, Czech Republic, ${ }^{2}$ Biomedical Centre, Faculty of Medicine in Pilsen, Charles University, Pilsen, Czech Republic, ${ }^{3}$ Department of Pathological Physiology, Faculty of Medicine in Pilsen, Charles University, Pilsen, Czech Republic, ${ }^{4}$ Department of Histology and Embryology, Faculty of Medicine in Pilsen, Charles University, Pilsen, Czech Republic

Received March 22, 2021

Accepted July 21, 2021

Epub Ahead of Print September 10, 2021

\section{Summary}

Diabetic foot ulcer (DFU) is a serious complication of diabetes and hyperbaric oxygen therapy (HBOT) is also considered in comprehensive treatment. The evidence supporting the use of HBOT in DFU treatment is controversial. The aim of this work was to introduce a DFU model in ZDF rat by creating a wound on the back of an animal and to investigate the effect of HBOT on the defect by macroscopic evaluation, quantitative histological evaluation of collagen (types I and III), evaluation of angiogenesis and determination of interleukin 6 (IL6) levels in the plasma. The study included 10 rats in the control group (CONT) and 10 in the HBOT group, who underwent HBOT in standard clinical regimen. Histological evaluation was performed on the $18^{\text {th }}$ day after induction of defect. The results show that HBOT did not affect the macroscopic size of the defect nor IL6 plasma levels. A volume fraction of type I collagen was slightly increased by HBOT without reaching statistical significance (1.35 \pm 0.49 and $1.94 \pm 0.67 \%$, CONT and HBOT, respectively). In contrast, the collagen type III volume fraction was 120\% higher in HBOT wounds $(1.41 \pm 0.81 \%)$ than in CONT ones $(0.63 \pm 0.37 \% ; p=0.046)$. In addition, the ratio of the volume fraction of both collagens in the wound $\left((\mathrm{I}+\mathrm{III})_{\mathrm{w}}\right)$ to the volume fraction of both collagens in the adjacent healthy skin $\left((\mathrm{I}+\mathrm{III})_{\mathrm{h}}\right)$ was $\sim 65 \%$ higher in rats subjected to HBOT $(8.9 \pm 3.07$ vs. $5.38 \pm 1.86 \%$, HBOT and CONT, respectively; $p=0.028)$. Vessels density (number per $1 \mathrm{~mm}^{2}$ ) was found to be higher in CONT vs. HBOT (206.5 \pm 41.8 and $124 \pm 28.2$, respectively, $p<0.001)$. Our
\end{abstract}

study suggests that HBOT promotes collagen III formation and decreases the number of newly formed vessels at the early phases of healing.

\section{Key words}

Hyperbaric oxygen • ZDF rat • Wound healing • Collagen type • Angiogenesis

\section{Corresponding author}

J. Ruzicka, Department of Biophysics, Faculty of Medicine in Pilsen, Alej Svobody 1655/76, 32300 Pilsen, Czech Republic. E-mail: jiri.ruzicka@lfp.cuni.cz

\section{Introduction}

Diabetic foot syndrome and its clinical manifestation in chronic defect - diabetic foot ulcer (DFU) remains a serious medical issue. It affects up to $34 \%$ of patients suffering from diabetes and it is the most common cause of non-traumatic amputation of the lower limb, where amputation is in $85 \%$ of cases preceded by DFU. The prevalence of DFU is about 4 to $10 \%$. (Jirkovská 2011, Apelquist 2008).

DFU has two principal pathophysiologic mechanisms that frequently overlap and potentiate each other: vasculopathy and neuropathy. Macroangiopathy typically affects infrapopliteal vessels, which leads to 
peripheral arterial disease of the lower extremities (Hobizal and Wukich 2012). Microangiopathy is associated with a loss of the elasticity of arterioles and capillaries due to lipid deposition and thickening of the basement membrane that results in altered nutrient exchange, tissue hypoxia and microcirculation ischemia. Diabetic neuropathy damages autonomic, sensory and motor nerves predisposing diabetic patients to trauma due to decreased protective sensation, impaired stability of joints due to muscle weakness and further impairment of microvascular blood flow due to direct damage to autonomic neurons caused by sorbitol accumulation, changes in the NAD:NADH ratio, and increased oxidative and nitrosative stress (Vinik et al. 2003, Packer et al. 2021).

Treatment of DFU must be complex, consisting of local and systemic approaches and adjunct methods if applicable in the given specific case (Waniczek et al. 2013). The basic principles of standard care are described in the International Working Group on the Diabetic Foot (IWGDF) guidelines (Lipsky et al. 2019). Standard treatment of the defect consists of assessment for infection, debridement, cleaning and proper dressings in addition to systemic glucose control and maintenance of adequate perfusion to the wound and lower extremities (Dreifke et al. 2015). In addition, 13 adjunct therapies were evaluated by IWGDF in 2019 and only 6 of them were recommended to be used in addition to the best standard of care (Rayman et al. 2020). Among them, the judicious use of hyperbaric oxygen therapy (HBOT) in certain non-healing ischemic ulcers was recommended (Rayman et al. 2020, Wu 2018).

Although the rationale for using HBOT in the treatment of DFU is well supported by the idea that overcoming wound hypoxia could expedite the healing process and promote epithelialisation (Aydin et al. 2013), many clinical and experimental studies on the putative beneficial effects of HBOT on wound healing brought about inconsistent results. Meta-analyses of clinical studies dealing with the impact of HBOT on the outcome of DFU concluded both beneficial and neutral effects of hyperbaric oxygen on the healing process of the defect and the risk of above-the-knee amputation (Brouwer et al. 2020, Kranke et al. 2015, Elraiyah et al. 2016, Margolis et al. 2013) pointing out the relatively high risk of bias and methodological limitations of some clinical studies taken into analyses. In addition, some recent clinical studies have suggested that HBOT may be used as a useful adjuvant to conservative standard therapy in the healing of DFU (Kumar et al. 2020, Teguh et al. 2020).

Animal studies dealing with the analyses of the efficiency of HBOT in the treatment of DFU also brought about controversial results. In an extensive study of HBOT effect on both non-ischemic and ischemic defects induced on the dorsal aspect of the hind feet of diabetic vs. normoglycemic rats, HBOT sped up the healing of ischemic and diabetic defects, but had no effect on nonischemic and normoglycemic defects (André-Lévigne et al. 2016). In a recent study performed on streptozotocin-diabetic mice, HBOT facilitated wound healing in DFU, promoted angiogenic activities of endothelial cells, activated HIF-1 $\alpha$ (hypoxia inducible factor) signaling, and promoted the expression of VEGF/SDF-1 (vascular endothelial growth factor/stromal cell derived factor) in fibroblast and the expression of the VEGF-R/CXCR4 receptor in endothelial cells (Huang et al. 2020). In contrast, other studies focused on HBOT effects in diabetic rodents did not show any improvement in macroscopic nor microscopic structure of the defect, perfusion of tissue in defect, long-term capillary-venous oxygen saturation, level of hemoglobin nor flow in microcirculation or formation of granulation tissue (or neo-dermis) after HBOT (van Neck et al. 2017, Tuk et al. 2014).

It should be noted that all the above mentioned experimental studies used animal model diabetes induced by streptozotocin, which corresponds more with Type 1 diabetes. Although DFU occurs in both Type 1 and Type 2 diabetes mellitus, Type 2 diabetes accounts for 90 to $95 \%$ of cases worldwide (Packer et al. 2021). As an animal model suitable for studying wound repair in Type 2 diabetes, Zucker Diabetic Fatty (ZDF) rat has been suggested (Slavkovsky et al. 2011). To our best knowledge, no study focusing on the effect of HBOT on DFU in ZDF rat has been performed so far.

The aim of the present study was to analyse the effect of HBOT on wound repair in ZDF rats. Standard square wounds were induced on the back of the experimental animals randomly assigned to control (ZDF rats) and experimental groups (ZDF rats subjected to HBOT in a clinically relevant protocol). The wounds were macroscopically evaluated twice per week in the course of 18 days. In addition, quantitative histological evaluation of collagens I and III was performed on day 18 of the experiment, along with microscopical evaluation of angiogenesis. The results of our study revealed a moderate beneficial effect of adjunct HBOT on the skin defect repair that should be further explored. 


\section{Methods}

The model of type 2 diabetes mellitus

Zucker Diabetic Fatty rats (ZDF rats) with a congenital mutation of the leptin receptor were used to develop the DFU model. ZDF rats were obtained from the Department of Toxicology and Laboratory Animals Breeding at the Institute of Experimental Pharmacology $\&$ Toxicology of the Slovak Academy of Sciences. The experimental animals, homozygous (fa/fa) males, were subsequently obtained by reproduction and selection at the author's workplace. The rats were housed individually throughout the experiment and received standard care according to EU directive 2010/63/EU including a 12/12 light schedule and free access to food and water.

Two months after birth rats were fed with highfat diet type 5008 (Purina 5008, Charles River, USA). After 4 months, the animals developed Type 2 diabetes mellitus with confirmed values of glycaemia higher than $15 \mathrm{mmol} / \mathrm{l}$ (glucometer MediTouch 2, Medisana, Germany) and possessed an obese phenotype. Twenty rats were randomly assigned to control (CONT; ZDF rats, $\mathrm{n}=10$ ) and experimental groups (HBOT; ZDF rats subjected to HBOT, $n=10$ ). The study was approved by the Animal Welfare Advisory Committee at the Faculty of Medicine in Pilsen and by the Ministry of Education, Youth and Sports of the Czech Republic (approval ID: MSMT 26570/2017-3). All experiments were performed in the Central Animal Facility of the Biomedical Centre at the Faculty of Medicine in Pilsen.

\section{Induction of wounds and evaluation of the wound size}

Wounds were induced in male diabetic rats at the average age of $140 \pm 12$ days and the average weight of $392 \pm 49 \mathrm{~g}$. The animals were premedicated with tramadol (10 mg/kg; Tramadol, Kalcex, Latvia) administered intraperitoneally in $4 \mathrm{ml}$ of tempered sterile saline and anaesthetized by inhalation of 2-3\% isoflurane (Aerrane, Baxter, Belgium) in oxygen using a face mask. Two square full-thickness $1.5 \times 1.5 \mathrm{~cm}$ wounds were made in the skin of the dorsal area of the rat, with the upper edge of the first wound reaching the scapula (Fig. 1). Tramadol in drinking water $(100 \mathrm{mg} / \mathrm{l}$; Tramal, oral solution, Stada Pharma, Germany) was then administered for the following 3 days. Pictures of wounds were taken (day 0) and wounds were covered with non-adhering dressing Cosmopor ${ }^{\circledR}$ E (Hartmann, Germany) and fixed by medical adhesive tape. The fourth day after induction of the wounds, the HBOT group began treatment in a hyperbaric chamber.

Twice per week the wounds in both CONT and HBOT groups were re-bandaged and pictures of them were taken until complete recovery or tissue sampling. Isoflurane anesthesia was used during the replacement of wound dressings and the documentation of wounds. Samples of wounds were taken at day 18 after wound induction followed by animal sacrifice and blood collection.
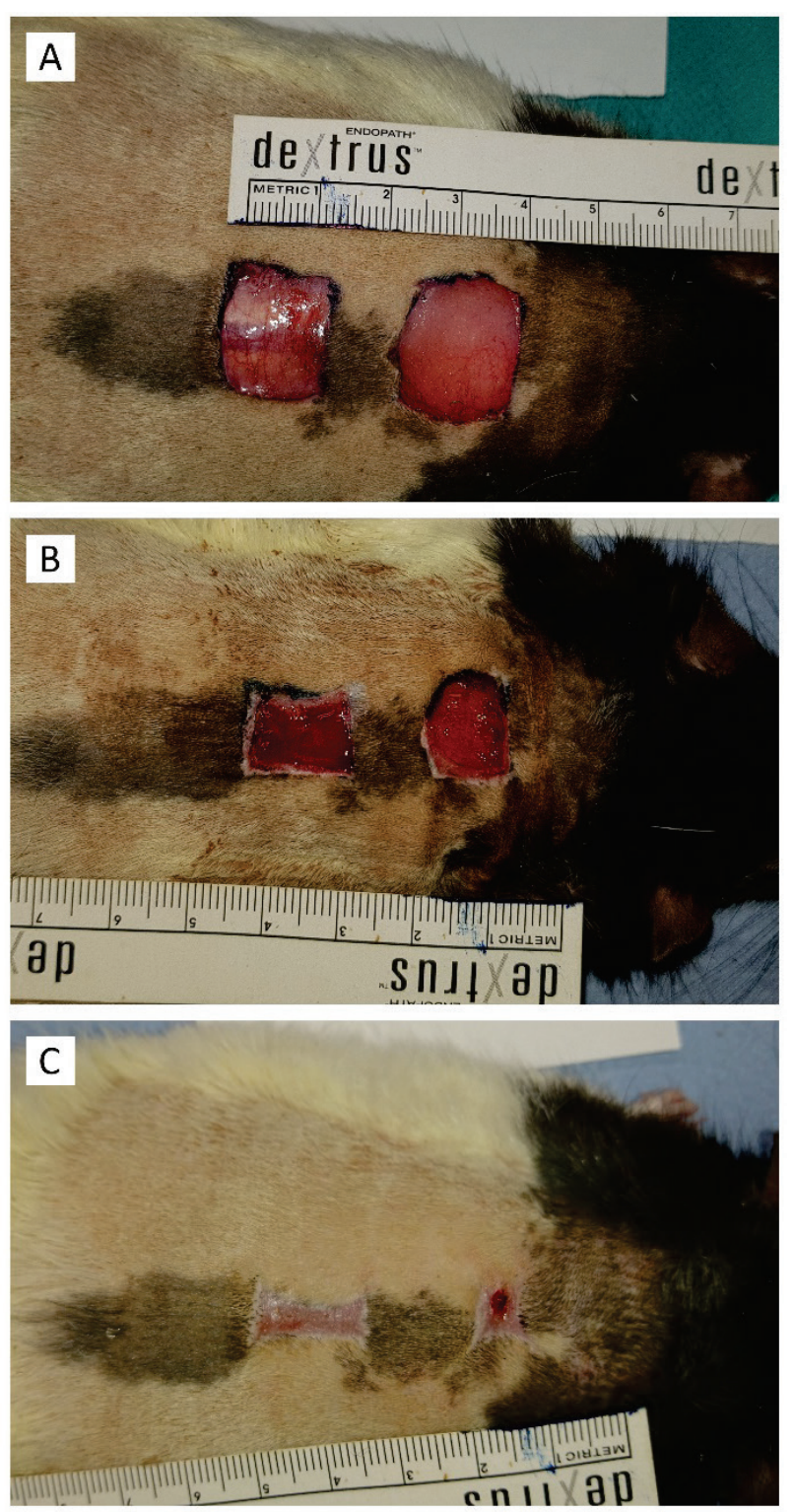

Fig. 1. Example of wounds created on the back of rat. (A) day 0 , (B) day $7,(\mathbf{C})$ day 18 of experiment.

Hyperbaric oxygen therapy (HBOT)

Standard animal cage $\left(3 \mathrm{H} ' 800 \mathrm{~cm}^{3}\right.$, Bioscape, Germany, EU directive 2010/63/EU) was technically 
improved to administer pure oxygen and to get air samples from the inner part. Our air pressurized hyperbaric chamber (CKD Prague, Czech Republic) was adapted to house this animal cage and equipped with connectors to supply gas into the cage and to take gas samples. On the day of treatment, animals were placed into this adapted cage. The cage in the chamber was washed with pure oxygen continuously. Each isocompression phase during the HBOT session lasted for $90 \mathrm{~min}$ at a pressure of $0.25 \mathrm{MPa}, 5$ times per week. This protocol is similar to the one used in clinical practice (Teguh et al. 2020, Kumar et al. 2020). During the whole treatment gas samples from the cage were taken in $10 \mathrm{~min}$ intervals to check if more than $95 \%$ oxygen levels were maintained.

\section{Macroscopic evaluation of wound area}

Pictures of skin defects were taken twice a week after the wound induction, i.e. on days $0,4,7,11,14$, and 18. The wound area $\left(\mathrm{mm}^{2}\right)$ was measured using ImageJ software (NIH, Bethesda, USA; Schneider et al. 2012). Wound size at each experimental animal was expressed in $\%$, calculated as wound area at a particular time point divided by wound area at day 4 (i.e. the day of initiation of HBOT). The exactness of measurements was raised by multiple evaluations (10 times) of one wound area.

\section{Quantitative histological evaluation of collagen}

The skin samples were fixed in $10 \%$ formaldehyde, dehydrated in ethanol and embedded in paraffin blocks. Two $5 \mu \mathrm{m}$-thick sections were stained using the haematoxylin-eosin (HE) to visualize the overall morphology. Other two sections were stained using picrosirius red (PSR, Merck Millipore, Darmstadt, Germany) to visualize type I collagen (yellow-red color when observed under polarized light) and type III collagen (green color under polarized light). The advantages of this method were well described (Rich and Whittaker 2005) and recently demonstrated in tissue engineering and in detail in the healing of skin wounds (East et al. 2018).

Briefly, the picrosirius red enhances the birefringence of co-aligned type I collagen fibrils and fibres. This phenomenon can be used for reproducible morphological quantification of the type I collagen content with high specificity and sensitivity (Junqueira et al. 1979). According to the thickness, type I collagen fibres appear in yellow (thinner fibres), orange, and red color (thick bundles of fibres). The green color and a weak birefringence represents type III collagen with loosely packed fibrils or very thin sections of the type I collaged fibres. The green color is not completely specific for the immature collagen, because the color and intensity of birefringence depends also on the section thickness (Junqueira et al. 1982). Linear polarization does not visualize all collagen fibres - those aligned parallel to the transmission axis remain dark, which results in underestimation of the total collagen content. To eliminate this orientation-mediated drawback, we applied circularly polarized illumination by using a circular polarizer (Hama, Monheim, Germany), while the analyser was constructed from a combination of a quarter-wave lambda plate placed below a linear polarizer (U-GAN, Olympus, Tokyo, Japan). Both filters were aligned in the crossed position using an Olympus CX41 microscope.

The samples stained with PSR were observed under circularly polarized light using the $20 \times$ objective. From each sample, two micrographs were captured representing the healthy skin adjacent to the healing lesion. Other two micrographs were sampled from the healing lesion. The amounts of the type I and the type III collagen were quantified as their volume fractions ( $\mathrm{Vv})$ within the two regions of interest, i.e. within the healthy skin, and within the healing lesion (Fig. 2). The volumes were quantified using the stereological grid point and the Cavalieri principle. This method of quantification of collagen has been previously established, extensively tested and proved as reliable and reroducible in several studies (Tonar et al. 2015, Horakova et al. 2018, Buzgo et al. 2019). The values are further presented as arithmetic mean values calculated from the micrographs per each animal and reference space. Moreover, the ratio of type III to type I collagen was calculated to investigate a possible reduction of type III collagen. This ratio is used as a measure of ongoing fibrillogenesis in early stages of wound healing (Mohammadzadeh et al. 2014).

\section{Quantitative histological evaluation of angiogenesis}

The skin samples were fixed in $10 \%$ formaldehyde, dehydrated in ethanol and embedded in paraffin blocks. Two $5 \mu \mathrm{m}$-thick histological sections were cut from each sample. The sections were deparaffinized and rehydrated. The blood vessels in the skin were detected immunohistochemically using polyclonal rabbit anti-human von Willebrand factor antibody (dilution 1:1000; DakoCytomation, Glostrup, Denmark). The reaction was visualized using diaminobenzidine as a part of the BOND polymer refine 
detection (Leica Biosystems Division of Leica Microsystems Inc., Buffalo Grove, United States).

Using $40 \times$ microscope objective, four micrographs were taken from each slide using systematic uniform random sampling (Tonar et al. 2008). The two- dimensional density of the microvessels profiles were quantified using the unbiased counting frame (Gundersen 1977) (Fig. 2). Stereological counting procedure was done using the Ellipse software (ViDiTo, Košice, Slovak Republic) (Witter et al. 2010).
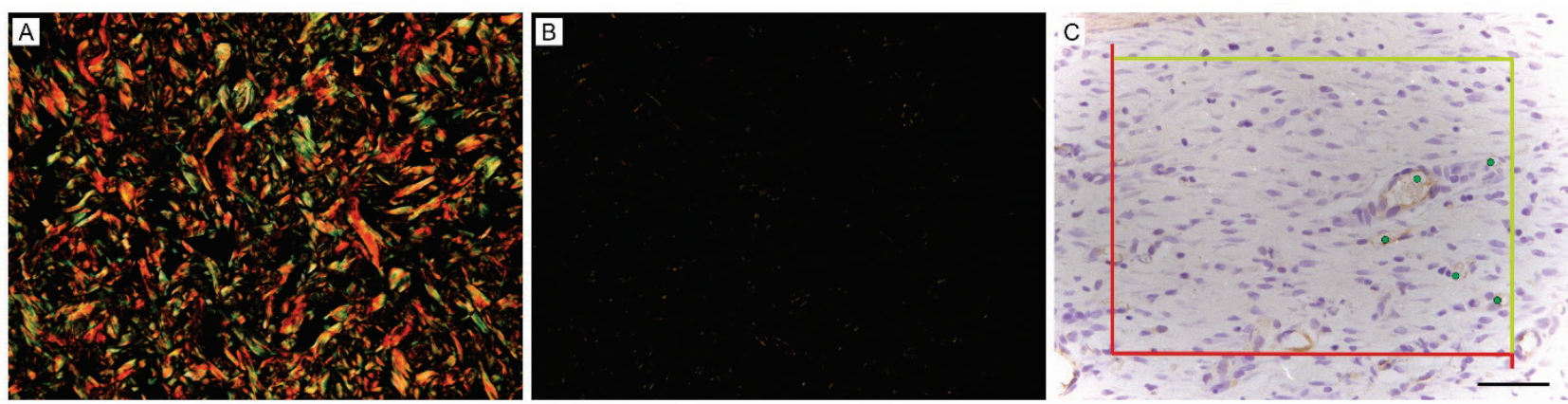

Fig. 2. Examples of histological evaluation. (A) skin without defect, Picrosirius red staining using polarized light to visualize type I collagen (yellow-red) and type III collagen (green), scale bar $50 \mu \mathrm{m}$. (B) healing skin defect, the same staining like A. (C) quantification of the microvessel density of the von Willebrand factor - positive vascular profiles (stained brown) in healing skin defect, red and green bars delimit area of interest, scale bar $50 \mu \mathrm{m}$.

\section{IL6 concentrations in the plasma}

Blood samples were taken from animals after their sacrifice by cardiac puncture to Li-heparin collection tubes. Samples were immediately centrifuged at $2000 \times \mathrm{g} 10 \mathrm{~min}$ at $4{ }^{\circ} \mathrm{C}$ and plasma was collected and stored at $-80{ }^{\circ} \mathrm{C}$ until analysis. IL6 concentration in plasma was determined by the Enzyme-Linked ImmunoSorbent Assay (ELISA) method using the RayBio ${ }^{\circledR}$ Rat IL6 ELISA Kit (RayBiotech, Peachtree Corners, Georgia, USA) according to the manufacturer's protocol.

\section{Data presentation and statistics}

Data are presented as means \pm standard deviation. Statistical inference was performed using $\mathrm{R}$ statistical software (R Development Core Team 2020). Residuals of all models were visually checked to detect potential heteroscedasticity and biased predictions. All statistical models were extended by a permutational approach (5000 randomizations), which estimates statistical significances reliably even if sample sizes are small and assumptions of the fully parametric methods are not met (Good 2005).

The effect of HBOT on the volume fractions of collagen (types I and III) in the scar were modelled via beta regression with logit-link function using the 'mgcv' R package (Wood 2011). The ratio between collagen I and III in the scar (log2-transformed to eliminate heteroscedasticity) and the relative volume fraction of both collagens in the wound compared to the volume fraction in the adjacent healthy skin were modelled with a general linear model. As the volume fractions of collagen III and the ratio between the collagen types I and III within wound correlated with the values from the adjacent healthy skin (within-subject correlation), and inclusion of the out-of-scar measurements into models improved parsimony of the models (reflected by the decrease of 'Bayesian Information Criterion' [BIC], Burnham and Anderson 1998), the measurements from the healthy skin were included as covariates. In these cases, only the factor 'treatment' was randomized in a permutation test whereas the response variable and the covariate were unchanged.

Similarly to analysis of collagen, angiogenesis was evaluated in wounds of both groups and in adjacent healthy tissue.

To evaluate the effect of HBOT on the speed of wound area shrinking (from day 4 to day 18), we employed a linear mixed-effects model (using the 'nlme' R package; Pinheiro et al. 2018) with animal identity representing a random-effect factor (random intercept) and 'day', 'treatment' and 'day X treatment' interaction representing fixed-effects predictors. We used the square root transformation of the wound size to eliminate heteroscedasticity in residuals. As categorization of the 'day' led to increased BIC and the wound size decreased approximately linearly with time, the 'day' was treated as a numerical (non-categorical) variable. Only 'treatment' 
was randomized (between the individuals) during the permutation test of the model.

\section{Results}

In the course of the first week after operation, 2 HBOT and 4 CONT rats died; these animals were excluded from the study that continued with 8 and 6 rats in the HBOT and CONT groups, respectively.

\section{Macroscopic evaluation of wound area}

The results of macroscopic evaluation are presented in Fig. 3 as a relative change in the defect size compared to the size on day 4 , when HBOT was initiated (i.e. relative to the day 4 defect area). The data indicated that the rats subjected to the HBOT group had no tendency to heal faster than the CONT rats. The difference did not reach statistical significance at any time point evaluated.

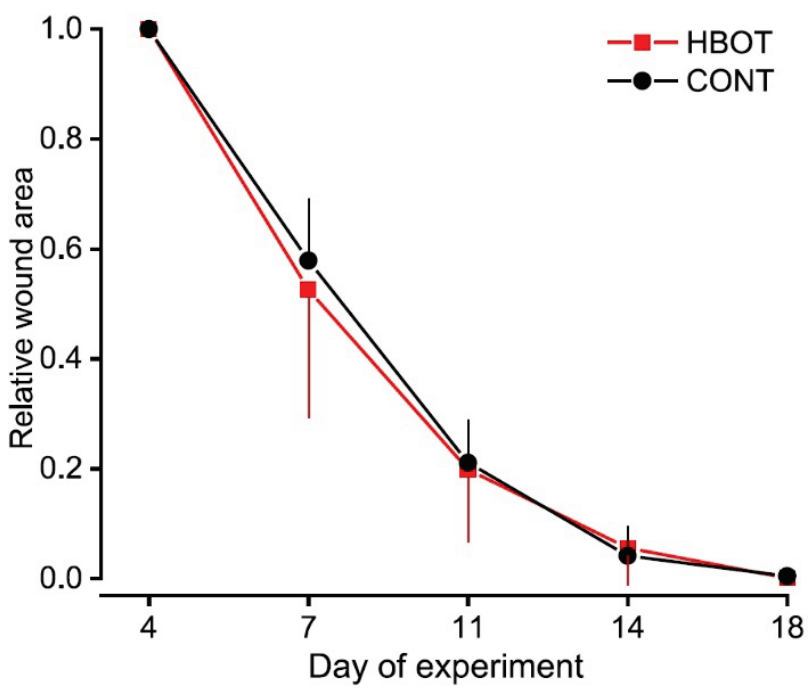

Fig. 3. Macroscopic evaluation of the wound. Wound area is relative to the area just before the first HBOT session (day 4 of the experiment). Data are means \pm SD.

\section{Quantitative histological evaluation of collagen}

The results of histological analyses of the defects are shown in Fig. 4A-D. HBOT had no significant effect on the volume fraction of collagens in the skin outside the defect. As expected, the volume fractions of both collagen subtypes were substantially smaller in the defects than in the surrounding skin. The fraction of type I collagen was $40 \%$ higher in the HBOT wounds than in the control ones, but the values did not reach statistical significance $(1.35 \pm 0.49$ and $1.94 \pm 0.67 \%$, CONT and HBOT, respectively; $\mathrm{p}=0.1$ ). In contrast, collagen type III fraction was $\sim 120 \%$ higher in HBOT wounds $(1.41 \pm 0.81 \%)$ than in CONT ones $(0.63 \pm 0.37 \%$; $\mathrm{p}=0.046)$. In addition, the ratio of the volume fraction of both collagens in the wound $\left((\mathrm{I}+\mathrm{III})_{\mathrm{w}}\right)$ to the volume fraction of both collagens in the adjacent healthy skin $\left((\mathrm{I}+\mathrm{III})_{\mathrm{h}}\right)$ was $\sim 65 \%$ higher in rats subjected to HBOT $(8.9 \pm 3.07$ vs. $5.38 \pm 1.86 \%$, HBOT and CONT, respectively; $p=0.028$ ). The collagen $\mathrm{I} /$ collagen III ratios did not differ significantly between the two groups (2.49 \pm 0.83 and $1.63 \pm 1.22$ in CONT and HBOT groups, respectively; $p=0.2$ ) in the defects and reached the values $5.63 \pm 4.18$ and $4.52 \pm 3.17$ in the adjacent healthy skin of CONT and HBOT rats.
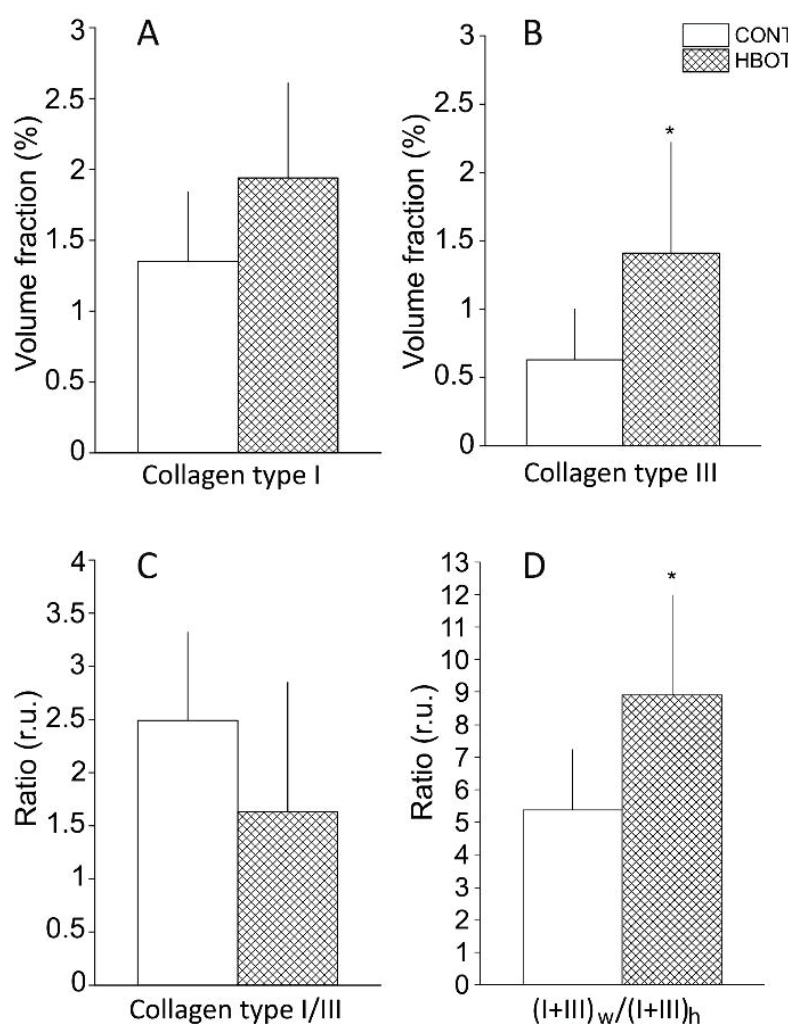

Fig. 4. Type I and type III collagen in the wound of control animals (CONT) and animals receiving hyperbaric oxygenotherapy (HBOT) after 18 days of healing. The volume fraction of type I collagen (A) and type III collagen (B) within the healing wound. The ratio between type I/type III collagens (C). The ratio between the volume fractions of both types of collagens within the wound to the volume fractions of both types of collagens within the adjacent healthy skin $\left((\mathrm{I}+\mathrm{III})_{\mathrm{w}} /(\mathrm{I}+\mathrm{III})_{\mathrm{h}}\right)$ (D). Values are means $\pm S D$, r.u. $=$ relative units; $* p<0.05$.

\section{Quantitative histological evaluation of angiogenesis}

Results are expressed as microvessel density (MVD), e.g. number of vessel profiles per $1 \mathrm{~mm}^{2}$. As expected, MVD was much higher in the wounds compared to adjacent healthy tissue $(206.5 \pm 41.8$ in the 
wound of CONT, $78.1 \pm 20.8$ in the healthy skin, $\mathrm{p}<0.001$ ). On the contrary, HBOT did not enhance vessel generation, our results show rather opposite effect (MVD $124 \pm 28.2$ in HBOT vs. $206.5 \pm 41.8$ in CONT, $p<0.001$ ).

\section{IL6 concentrations in the plasma}

IL6 levels in the plasma of both CONT and HBOT rats did not exceed the detection limit of the kit, i.e. $30 \mathrm{pg} / \mathrm{ml}$.

\section{Discussion}

The present study analyses the effects of HBOT on several parameters of wound healing in ZDF rats. The selected animal model is widely used in experimental practice to study the pathophysiology and secondary complications of Type 2 diabetes (Siwy et al. 2012). The ZDF model has also proven to be useful in evaluating the impact of diabetes on wound healing and neuropathy (Otto et al. 2011, Slavkovsky et al. 2011). Nevertheless, the effect of HBOT on the skin repair processes has been analyzed so far only in streptozotocin-induced diabetic rats with conflicting results (see Introduction).

Our study focused not only on the speed of reduction of the wound area, but also on the quantitative analysis of collagens I and III in the wound tissue and surrounding intact skin since the new production of collagen, its spatial distribution and metabolism play a major role in the restoration of homeostasis during the repair of skin defects (Wynn 2008). Histological evaluation of healing wounds often includes the rating of type I and type III collagens expressed as volume fractions (Clore et al. 1979, Dale et al. 1996, Wang et al. 2017).

Although macroscopic evaluation of the wound area did not show any trend to faster skin repair after HBOT, histological analysis brought about interesting outcomes. HBOT had a significant impact on collagen formation in the injured tissue leading to an increased volume fraction of collagen III at day 18 of the experiment, i.e. after 10 completed sessions of HBOT. In the study performed on B6.BKS(D)-Lepr $\mathrm{db} / \mathrm{db}$ adult diabetic mice (spontaneous Type 2 diabetic mouse model with a low capacity to regenerate skin), the skin defect was created on the dorsal surface of the animal and a silicone O-ring was placed surrounding the wound and attached to the skin to prevent wound-healing by contraction. In this setting, the authors documented accelerated healing in animals subjected to HBOT (Pena-
Villalobos et al. 2018); however, no such ring was used in our study. The authors hypothesized that faster skin repair in hyperbaric oxygen conditions might improve collagen synthesis and epithelization in the wound bed. In our experiments, contraction of the wounds was not prevented, which might overlay the potential beneficial effect of HBOT on other repair processes. Nevertheless, the wound skin area of rats subjected to HBOT displayed a $\sim 120 \%$ higher volume fraction of collagen III and a $\sim 65 \%$ higher ratio of both collagens in the healing wound to intact surrounding skin, suggesting that the repair process was indeed accelerated by HBOT.

Wound healing is a complex sophisticated series of events resulting in the replacement of injured or missing tissue. The process of skin repair is usually described in three overlapping stages: inflammation, proliferation and tissue remodelling (Guo and DiPietro 2010, Velnar et al. 2009, Young and McNaught 2011). The inflammatory response to injury is mediated by damaged cells, resident immune cells and neutrophils and macrophages recruited in response to chemokines released from the tissue. The proliferative stage comprises angiogenesis, reepithelialisation, and fibroplasia aiming to decrease the area of lesioned tissue and create a new efficient barrier against the external environment. Fibroblasts recruited from the dermis of the adjacent skin proliferate in response to a number of cytokines, e.g. transforming growth factor- $\beta$ (TGF- $\beta$ ) or platelet-derived growth factor (PDGF) (Guo and DiPietro 2010, Velnar et al. 2009, Young and McNaught 2011) and participate in collagen synthesis in the proliferative and remodeling phases of wound healing. The highest amounts of type III collagen appear five days after injury and contribute to the scar formation. During later phases of healing, i.e. remodelling, type I collagen is formed from the precursor type III collagen. The resulting new type I collagen, made of thicker and longer fibrils than the type III collagen, provides strength and mechanical stability (Campelo et al. 2018, Wang et al. 2015, Young and McNaught 2011).

We have not found any positive effect of HBOT on angiogenesis, on the contrary HBOT seemed to inhibit new vessel formation. This controversial result might be explained by complex reasons. Our evaluation $\left(18^{\text {th }}\right.$ day after operation) was performed relatively late, when defects were almost healed. It should be noted that angiogenesis is rapid in the early phase of healing, supported by inflammation and in the later phases of healing, number of vessels decreases again (Di Pietro 
2016). Other studies suggest that angiogenesis is supported by HBOT only in hypoxic tissues like in defects on leg after arterial ligation, skin grafts, contused mussels etc. (Huang et al. 2020, Yamamoto et al. 2020, Buckley and Cooper 2021, Yu et al. 2019). It is thus possible that in our setting, HBOT accelerated angiogenetic processes and at the time of evaluation, we did not detect the peak value of the density of newly formed vessels. In addition, our defects on rat back probably did not suffer from hypoxia.

In our study, we have not revealed any trend to general inflammation as documented by IL6 levels in the plasma that barely exceeded the detection limit of the assay with no difference between CONT and HBOT rats. Collagen I volume fraction in the healing skin of HBOT rats was $\sim 40 \%$ higher than in CONT animals, however this difference did not reach statistical significance $(p=0.09)$. Taken together, our study suggests that HBOT promotes collagen III formation at least in the early phases of healing of uncomplicated skin defects in ZDF rats as documented by its increased volume fraction and elevated ratio of collagen I+III content in the wound area to intact surrounding skin.

\section{Study limitations}

Increased collagen III content in the wound area after HBOT does not necessarily mean that the healing process was really improved as this type collagen formation is typical for the initial phase of healing and final mechanical stability of the scar is mainly dependent on the conversion of type III to type I collagen. The collagen I/III ratio in healthy rat skin ranges between 4.6 and 8.5 and it is taken as an indicator of the quality of the collagen fibres network (Clore et al. 1979, Dale et al. 1996, Wang et al. 2017). In our analysis of the skin outside the wound this ratio reached the values $5.63 \pm 4.18$ and 4.52 \pm 3.17 in CONT and HBOT rats, respectively.
The decreased collagen I/III ratio could imply lower connective tissue tensile strength (Klinge et al. 2000) and typically occurs in immature skin wounds before the final scar remodelling (Fleischmajer et al. 1990). Although no significant difference in this ratio was noticed in the wound area, HBOT tended to decrease it to $1.63 \pm 1.22$ compared to CONT wounds $(2.49 \pm 0.83)$.

It thus would be useful to extend the experiment duration to also map the later phases of healing and final collagen composition of the scarred tissue to verify the putative beneficial effect of HBOT on the final quality of the scar.

Although the original area of the skin defect was relatively large (200 to $300 \mathrm{~mm}^{2}$ ), the wounds nearly completely closed by day 18 of the experiment in both CONT and HBOT rats. For the following experiments focused on wound healing in ZDF rats, prevention of the defect contraction could be helpful in the detailed evaluation of individual healing stages.

Another limitation was that our study did not follow any damage to the innervation of the wound, although loss of cutaneous innervation from sensory neuropathy is included among mechanisms for impaired healing of diabetic skin wounds (Cheng et al. 2013). However, it was previously shown that the Type 2 diabetes in ZDF rats is accompanied with functional alteration of peripheral nerves (Katsuda et al. 2014).

\section{Conflict of Interest}

There is no conflict of interest.

\section{Acknowledgements}

This study was supported by project No. CZ 02.1.01/0.0/0.0/16-019/0000787 Fighting INfection Disseases, financed from EFRR, by program PROGRESS Q39, by the Ministry of Health of the Czech Republic Project number NV18-01-00332 and by Charles University Project No. SVV 260536.

\section{References}

ANDRÉ-LÉVIGNE D, MODARRESSI A, PIGNEL R, BOCHATON-PIALLAT ML, PITTET-CUÉNOD B: Hyperbaric oxygen therapy promotes wound repair in ischemic and hyperglycemic conditions, increasing tissue perfusion and collagen deposition. Wound Repair Regen 24: 954-965, 2016. https://doi.org/10.1111/wrr.12480

APELQVIST J: The foot in perspective. Diabetes Metab Res Rev 24 (Suppl 1): 110-115, 2008. https://doi.org/10.1002/dmrr.834

AYDIN F, KAYA A, KARAPINAR L, KUMBARACI M, IMERCI A, KARAPINAR H, KARAKUZU C, INCESU M: IGF-1 increases with hyperbaric oxygen therapy and promotes wound healing in diabetic foot ulcers. J Diabetes Res 2013: 567834, 2013. https://doi.org/10.1155/2013/567834 
BROUWER RJ, LALIEU RC, HOENCAMP R, VAN HULST RA, UBBINK DT: A systematic review and meta-analysis of hyperbaric oxygen therapy for diabetic foot ulcers with arterial insufficiency. J Vasc Surg 71: 682-692, 2020. https://doi.org/10.1016/i.jvs.2019.07.082

BUCKLEY CJ, COOPER JS: Hyperbaric affects on angiogenesis. StatPearls [Internet]. Treasure Island (FL): StatPearls Publishing; 2021. https:/www.ncbi.nlm.nih.gov/books/NBK482485/

BURNHAM KP, ANDERSON DR: Model Selection and Inference. Springer, New York, 1998,355 p. https://doi.org/10.1007/978-1-4757-2917-7

BUZGO M, PLENCNER M, RAMPICHOVA M, LITVINEC A, PROSECKA E, STAFFA A, KRALOVIC M, FILOVA E, DOUPNIK M, LUKASOVA V, VOCETKOVA K, ANDEROVA J, KUBIKOVA T, ZAJICEK R, LOPOT F, JELEN K, TONAR Z, AMLER E, DIVIN R, FIORI F: Poly-e-caprolactone and polyvinyl alcohol electrospun wound dressings: adhesion properties and wound management of skin defects in rabbits. Regen Med 14: 423-445, 2019. https://doi.org/10.2217/rme-2018-0072

CAMPELO MBD, SANTOS JAF, FILHO ALM, FERREIRA DCL, SANT'ANNA LB, OLIVEIRA RA, MAIA LF, ARISAWA EÂL: Effects of the application of the amniotic membrane in the healing process of skin wounds in rats. Acta Cir Bras 33: 144-155, 2018. https://doi.org/10.1590/s0102-865020180020000006

CHENG C, SINGH V, KRISHNAN A, KAN M, MARTINEZ JA, ZOCHODNE DW: Loss of innervation and axon plasticity accompanies impaired diabetic wound healing. PLoS One 8: e75877, 2013. https://doi.org/10.1371/journal.pone.0075877

CLORE JN, COHEN IK, DIEGELMANN RF: Quantitation of collagen types I and III during wound healing in rat skin. Proc Soc Exp Biol Med 161: 337-340, 1979. https://doi.org/10.3181/00379727-161-40548

DALE PD, SHERRATT JA, MAINI PK: A mathematical model for collagen fibre formation during foetal and adult dermal wound healing. Proc Biol Sci 263: 653-660, 1996. https://doi.org/10.1098/rspb.1996.0098

DIPIETRO LA: Angiogenesis and wound repair: when enough is enough. J Leukoc Biol 100: 979-984, 2016. https://doi.org/10.1189/jlb.4MR0316-102R

DREIFKE MB, JAYASURIYA AA, JAYASURIYA AC: Current wound healing procedures and potential care. Mater Sci Eng C Materl Biol Appl 48: 651-662, 2015. https://doi.org/10.1016/j.msec.2014.12.068

EAST B, PLENCNER M, KRALOVIC M, RAMPICHOVA M, SOVKOVA V, VOCETKOVA K, OTAHAL M, TONAR Z, KOLINKO Y, AMLER E, HOCH J: A polypropylene mesh modified with poly- $\varepsilon$-caprolactone nanofibers in hernia repair: large animal experiment. Int J Nanomedicine 13: 3129-3143, 2018. https://doi.org/10.2147/IJN.S159480

ELRAIYAH T, TSAPAS A, PRUTSKY G, DOMECQ JP, HASAN R, FIRWANA B, NABHAN M, PROKOP L, HINGORANI A, CLAUS PL, STEINKRAUS LW, MURAD MH: A systematic review and meta-analysis of adjunctive therapies in diabetic foot ulcers. J Vasc Surg 63: 46S-58S.e1-2, 2016. https://doi.org/10.1016/j.jvs.2015.10.007

FLEISCHMAJER R, PERLISH JS, BURGESON RE, SHAIKH-BAHAI F, TIMPL R: Type I and type III collagen interactions during fibrillogenesis. Ann N Y Acad Sci 580: 161-175, 1990. https://doi.org/10.1111/j.17496632.1990.tb17927.x

GOOD PI: Permutation, Parametric and Bootstrap Tests of Hypotheses. Springer, New York, 2005,316 p. https://doi.org/10.1007/b138696

GUNDERSEN HJG: Notes on the estimation of the numerical density of arbitrary profiles: the edge effect. J Microsc 111: 219-223, 1977. https://doi.org/10.1111/j.1365-2818.1977.tb00062.x

GUO S, DIPIETRO LA: Factors affecting wound healing. J Dent Res 89: 219-229, 2010. https://doi.org/10.1177/0022034509359125

HOBIZAL KB, WUKICH DK: Diabetic foot infections: current concept review. Diabetic Foot Ankle 3: $18409,2012$. https://doi.org/10.3402/dfa.v3i0.18409

HORAKOVA J, MIKES P, LUKAS D, SAMAN A, JENCOVA V, KLAPSTOVA A, SVARCOVA T, ACKERMANN M, NOVOTNY V, KALAB M, LONSKY V, BARTOS M, RAMPICHOVA M, LITVINEC A, KUBIKOVA T, TOMASEK P, TONAR Z: Electrospun vascular grafts fabricated from poly(L-lactide-co- $\varepsilon$-caprolactone) used as a bypass for the rabbit carotid artery. Biomed Mater 13: 065009, 2018. https://doi.org/10.1088/1748-605X/aade9d 
HUANG X, LIANG P, JIANG B, ZHANG P, YU W, DUAN M, GUO L, CUI X, HUANG M, HUANG X: Hyperbaric oxygen potentiates diabetic wound healing by promoting fibroblast cell proliferation and endothelial cell angiogenesis. Life Sci 259: 118246, 2020. https://doi.org/10.1016/j.lfs.2020.118246

HUANG X, LIANG P, JIANG B, ZHANG P, YU W, DUAN M, GUO L, CUI X, HUANG M, HUANG X: Hyperbaric oxygen potentiates diabetic wound healing by promoting fibroblast cell proliferation and endothelial cell angiogenesis. Life Sci 259: 118246, 2020. https://doi.org/10.1016/j.1fs.2020.118246

JIRKOVSKÁ A: Adherence to the international guidelines on the treatment of diabetic leg syndrome. Vnitr Lek 57: 908-912, 2011.

JUNQUEIRA LCU, BIGNOLAS G, BRENTANI RR: Picrosirius staining plus polarization microscopy, a specific method for collagen detection in tissue sections. Histochem J 11: 447-455, 1979. https://doi.org/10.1007/BF01002772

JUNQUEIRA LCU, MONTES GS, SANCHEZ EM: The influence of tissue section thickness on the study of collagen by the Picrosirius-polarization method. Histochemistry 74: 153-156, 1982. https://doi.org/10.1007/BF00495061

KATSUDA Y, OHTA T, MIYAJIMA K, KEMMOCHI Y, SASASE T, TONG B, SHINOHARA M, YAMADA T: Diabetic complications in obese type 2 diabetic rat models. Exp Anim 63: 121-132, 2014. https://doi.org/10.1538/expanim.63.121

KLINGE U, SI Z, ZHENG H, SCHUMPELICK V, BHARDWAJ S, KLOSTERHALFEN B: Abnormal collagen I to III distribution in the skin of patients with incisional hernia. Eur Surg Res 32: 43-48, 2000. https://doi.org/10.1159/000008740

KRANKE P, BENNETT MH, MARTYN-ST JAMES M, SCHNABEL A, DEBUS SE, WEIBEL S: Hyperbaric oxygen therapy for chronic wounds. Cochrane Database Syst Rev 2015: CD004123, 2015. https://doi.org/10.1002/14651858.CD004123.pub4

KUMAR A, SHUKLA U, PRABHAKAR T, SRIVASTAVA D: Hyperbaric oxygen therapy as an adjuvant to standard therapy in the treatment of diabetic foot ulcers. J Anaesthesiol Clin Pharmacol 36: 213-218, 2020. https://doi.org/10.4103/joacp.JOACP 94_19

LIPSKY BA, SENNEVILLE É, ABBAS ZG, ARAGÓN-SÁNCHEZ J, DIGGLE M, EMBIL JM, KONO S, LAVERY LA, MALONE M, VAN ASTEN SA, URBANČIČ-ROVAN V, PETERS EJG; International Working Group on the Diabetic Foot (IWGDF): Guidelines on the diagnosis and treatment of foot infection in persons with diabetes (IWGDF 2019 update). Diabetes Metab Res Rev 36 (Suppl 1): e3280, 2020. https://doi.org/10.1002/dmrr.3280

MARGOLIS DJ, GUPTA J, HOFFSTAD O, PAPDOPOULOS M, GLICK HA, THOM SR, MITRA N: Lack of effectiveness of hyperbaric oxygen therapy for the treatment of diabetic foot ulcer and the prevention of amputation: a cohort study. Diabetes Care 36: 1961-1966, 2013. https://doi.org/10.2337/dc12-2160

MOHAMMADZADEH E, NIKRAVESH MR, JALALI M, FAZEL A, EBRAHIMI V, EBRAHIMZADEHBIDESKAN AR: Immunohistochemical study of type III collagen expression during pre and post-natal rat skin morphogenesis. Iran J Basic Med Sci 17: 196-200, 2014.

OTTO KJ, WYSE BD, CABOT PJ, SMITH MT: Longitudinal study of painful diabetic neuropathy in the Zucker diabetic fatty rat model of type 2 diabetes: impaired basal G-protein activity appears to underpin marked morphine hyposensitivity at 6 months. Pain Med 12: 437-450, 2011. https://doi.org/10.1111/j.1526-4637.2011.01067.x

PACKER CF, ALI SA, MANNA B: Diabetic ulcer. StatPearls, Treasure Island (FL), StatPearls Publishing, PMID $29763062,2021$.

PEÑA-VILLALOBOS I, CASANOVA-MALDONADO I, LOIS P, PRIETO C, PIZARRO C, LATTUS J, OSORIO G, PALMA V: Hyperbaric oxygen increases stem cell proliferation, angiogenesis and wound-healing ability of WJ-MSCs in diabetic mice. Front Physiol 9: 995, 2018. https://doi.org/10.3389/fphys.2018.00995

PINHEIRO J, BATES D, DEBROY S, SARKAR D, R CORE TEAM: nlme: Linear and nonlinear mixed effects models. 2018. https://cran.r-project.org/web/packages/nlme/citation.html. Accessed September 24, 2018.

R Development Core Team: R: A Language and Environment for Statistical Computing. 2020. https://www.rproject.org/.

RAYMAN G, VAS P, DHATARIYA K, DRIVER V, HARTEMANN A, LONDAHL M, PIAGGESI A, APELQVIST J, ATTINGER C, GAME F; International Working Group on the Diabetic Foot (IWGDF): Guidelines on use of interventions to enhance healing of chronic foot ulcers in diabetes (IWGDF 2019 update) Diabetes Metab Res Rev 36: e3283, 2020. https://doi.org/10.1002/dmrr.3283 
RICH L, WHITTAKER P: Collagen and picrosirius red staining: A polarized light assessment of fibrillar hue and spatial distribution. J Morphol Sci 22: 97-104, 2005.

SCHNEIDER CA, RASBAND WS, ELICEIRI KW: NIH Image to ImageJ: 25 years of image analysis. Nat Methods 9: 671-675, 2012. https://doi.org/10.1038/nmeth.2089

SIWY J, ZOJA C, KLEIN J, BENIGNI A, MULLEN W, MAYER B, MISCHAK H, JANKOWSKI J, STEVENS R, VLAHOU A, KOSSIDA S, PERCO P, BAHLMANN FH: Evaluation of the Zucker diabetic fatty (ZDF) rat as a model for human disease based on urinary peptidomic profiles. PLoS One 7: e51334, 2012. https://doi.org/10.1371/journal.pone.0051334

SLAVKOVSKY R, KOHLEROVA R, TKACOVA V, JIROUTOVA A, TAHMAZOGLU B, VELEBNY V, REZAČOVÁ M, SOBOTKA L, KANTA J: Zucker diabetic fatty rat: a new model of impaired cutaneous wound repair with type II diabetes mellitus and obesity. Wound Repair Regen 19: 515-525, 2011. https://doi.org/10.1111/j.1524-475X.2011.00703.x

TEGUH DN, BOL RAAP R, KOOLE A, KNIPPENBERG B, SMIT C, OOMEN J, VAN HULST RA: Hyperbaric oxygen therapy for nonhealing wounds: Treatment results of a single center. Wound Repair Regen 2020: 1-7, 2020. https://doi.org/10.1111/wrr.12884

THIRUVOTH FM, MOHAPATRA DP, KUMAR D, CHITTORIA RK, NANDHAGOPAL V: Current concepts in the physiology of adult wound healing. Plast Aesthet Res 2015: 250-256, 2015. https://doi.org/10.4103/2347$\underline{9264.158851}$

TONAR Z, KUBÍKOVÁ T, PRIOR C, DEMJÉN E, LIŠKA V, KRÁLÍČKOVÁ M, WITTER K: Segmental and age differences in the elastin network, collagen, and smooth muscle phenotype in the tunica media of the porcine aorta. Ann Anat 201: 79-90, 2015. https://doi.org/10.1016/j.aanat.2015.05.005

TONAR Z, EGGER GF, WITTER K, WOLFESBERGER B: Quantification of microvessels in canine lymph nodes. Microsc Res Tech 71: 760-772, 2008. https://doi.org/10.1002/jemt.20619

TUK B, TONG M, FIJNEMAN EMG, VAN NECK JW: Hyperbaric oxygen therapy to treat diabetes impaired wound healing in rats. PLoS One 9: e108533, 2014. https://doi.org/10.1371/journal.pone.0108533

VAN NECK JW, TUK B, FIJNEMAN EMG, REDEKER JJ, TALAHATU EM, TONG M: Hyperbaric oxygen therapy for wound healing in diabetic rats: Varying efficacy after a clinically-based protocol. PLoS One 12, e0177766, 2017. https://doi.org/10.1371/journal.pone.0177766

VELNAR T, BAILEY T, SMRKOLJ V: The wound healing process: an overview of the cellular and molecular mechanisms. J Int Med Res 37: 1528-1542, 2009. https://doi.org/10.1177/147323000903700531

VINIK AI, MASER RE, MITCHELL BD, FREEMAN R: Diabetic autonomic neuropathy. Diabetes Care 26: 1553-1579, 2003. https://doi.org/10.2337/diacare.26.5.1553

WANG T, GU Q, ZHAO J, MEI J, SHAO M, PAN Y, ZHANG J, WU H, ZHANG Z, LIU F: Calcium alginate enhances wound healing by up-regulating the ratio of collagen types I/III in diabetic rats. Int J Clin Exp Pathol 8: 6636-6645, 2015.

WANG Z, WANG Q, WANG L, XU W, HE Y, LI Y, HE S, MA H: Improvement of skin condition by oral administration of collagen hydrolysates in chronologically aged mice. J Sci Food Agric 97: 2721-2726, 2017. https://doi.org/10.1002/jsfa.8098

WANICZEK D, KOZOWICZ A, MUC-WIERZGOŃ M, KOKOT T, SWIĘTOCHOWSKA E, NOWAKOWSKAZAJDEL E: Adjunct methods of the standard diabetic foot ulceration therapy. Evid Based Complement https://doi.org/10.1155/2013/243568

WITTER K, TONAR Z, MATEJKA VM, MARTINCA T, JONÁK M, ROKOSNÝ S, PIRK J: Tissue reaction to three different types of tissue glues in an experimental aorta dissection model: a quantitative approach. Histochem Cell Biol 133: 241-259, 2010. https://doi.org/10.1007/s00418-009-0656-3

WOOD SN: Fast stable restricted maximum likelihood and marginal likelihood estimation of semiparametric generalized linear models. J Royal Stat Soc Stat Methodol 73: 3-36, 2011. https://doi.org/10.1111/j.1467-9868.2010.00749.x

WU Q: Hyperbaric oxygen for treatment of diabetic foot ulcers: love you more than I can say. Ann Transl Med 6: 228, 2018. https://doi.org/10.21037/atm.2018.04.33

WYNN TA: Cellular and molecular mechanisms of fibrosis. J Pathol 214: 199-210, 2008. https://doi.org/10.1002/path.2277 
YAMAMOTO N, OYAIZU T, ENOMOTO M, HORIE M, YUASA M, OKAWA A, YAGISHITA K: VEGF and bFGF induction by nitric oxide is associated with hyperbaric oxygen-induced angiogenesis and muscle regeneration. Sci Rep 10: 2744, 2020. https://doi.org/10.1038/s41598-020-59615-x

YOUNG A, MCNAUGHT CE: The physiology of wound healing. Surgery 29: 475-479, 2011. https://doi.org/10.1016/j.mpsur.2011.06.011

YU M, YUAN HS, LI Q, LI Q, TENG YF: Combination of cells-based therapy with apelin-13 and hyperbaric oxygen efficiently promote neovascularization in ischemic animal model. Eur Rev Med Pharmacol Sci 23: 2630-2639, 2019. https://doi.org/10.26355/eurrev_201903_17413 